\begin{tabular}{|lll|}
\hline Diterima & $:$ & 2 Oktober 2020 \\
Direvisi & $:$ & 21 Januari 2021 \\
Disetujui & $:$ & 30 Juni 2021 \\
Diterbitkan & $:$ & 30 Juni 2021 \\
\hline
\end{tabular}

\title{
PERBEDAAN POLA PENGASUHAN ORANG TUA PADA ANAK USIA DINI DITINJAU DARI BERBAGAI SUKU DI INDONESIA: KAJIAN LITERATUR
}

\author{
Arifah Prima Satrianingrum ${ }^{1} \&$ Farida Agus Setyawati ${ }^{2}$ \\ email: aprimasatrianingrum@yahoo.com ${ }^{1}$, faridaagus@uny.ac.id ${ }^{2}$ \\ Program Studi S2 Pendidikan Anak Usia Dini, Universitas Negeri Yogyakarta1 \\ Program Studi Psikologi, Universitas Negeri Yogyakarta² \\ Jalan Colombo No. 1, Karangmalang, Yogyakarta 5528, Indonesia
}

\begin{abstract}
Abstrak: Berbagai faktor memengaruhi setiap keluarga dalam mengaplikasikan pola asuh yang diterapkan untuk anaknya. Salah satu faktor yang memengaruhi pola pengasuhan adalah suku dan budaya yang dipegang teguh oleh orang tua. Tujuan penelitian ini ialah memaparkan kajian tentang adanya perbedaan pola asuh yang dilakukan oleh orang tua dengan latar belakang suku yang berbeda kepada anaknya. Penelitian ini menggunakan kajian literatur yang bersumber dari hasil-hasil penelitian yang sudah dilakukan, buku, dokumen yang tertera secara daring maupun cetak. Hasil studi literatur ini menunjukkan bahwa perbedaan pola asuh di setiap suku di Indonesia dipengaruhi oleh faktor-faktor, seperti adat, kebiasaan, dan lain sebagainya.
\end{abstract}

Kata-kata Kunci: anak usia dini, budaya, kajian literatur, pola asuh, suku di Indonesia

\section{THE DIFFERENCES OF PARENTING PATTERN ASSESSED FROM VARIOUS TRIBES IN INDONESIA: LITERATURE REVIEW}

\begin{abstract}
Every family is influenced by various factors in applying the pattern of parenting to their children. One of the factors that influence pattern of parenting is the ethnicity and culture that parents adhere to. This study purpose is to report differences in parenting patterns that were influenced by the ethnicity of parents towards their children. This is a literature review sourced from secondary sources from several research results that have been carried out, books, documents that are listed online and in print. This study shows that differences in parenting styles in each ethnic group in Indonesia are influenced by factors in each tribe such as customs and habits.
\end{abstract}

Keywords: preschool children, culture, literature review, pattern of parenting, tribes in Indonesia

\section{PENDAHULUAN}

Indonesia kaya dengan beraneka ragam budaya, bahasa, adat istiadat, suku dan berbagai macam lainnya. Penduduk Indonesia yang mencapai 267,7 juta jiwa (BPS, 2020), menambah variasi ragam Indonesia. Bhinneka Tunggal lka adalah semboyan yang diagungkan oleh Indonesia, karena beragam variasi yang mengisi penjuru negeri, tapi hidup dengan damai dan saling bergotong royong. "Berbeda-beda, tapi tetap satu". Dengan banyaknya jenis budaya yang ada, banyak yang dapat dipelajari dari Indonesia, salah satunya objek budaya yang memberikan banyak penjelasan. Hal ini merupakan salah satu aspek potensial yang dimiliki oleh Indonesia (Situngkir, 2008). Kebudayaan di setiap daerah memiliki sikap dan 
nilai yang berbeda-beda. Pada suku Minang, anak harus mengikuti garis keturunan Ibu atau matrilineal. Namun, pada suku Batak, anak harus mengikuti garis keturunan ayah atau patrilineal. Masyarakat mengaplikasikan kebiasaannya dari apa yang telah ia dapatkan dari nenek moyang. Kebudayaan tersebut diterapkan secara turun menurun, sehingga dapat dilestarikan nilai dan kebiasaannya, agar bertambahnya pengetahuan individu mengenai nilai suatu kelompok (Sung, 2010).

Pewarisan standar dan nilai yang telah ditetapkan oleh masyarakat setempat diturunkan kepada generasi selanjutnya. Ini disebut dengan enkulturasi (Merliana, 2010). Proses enkulturasi memerlukan proses yang sangat panjang, sehingga generasi selanjutnya yang menerima nilai dan budaya tersebut dapat memegang teguh hingga menjadi kebiasaan (habit). Pembudayaan (enkulturasi) ini dapat dilakukan di berbagai tempat, namun untuk hasil yang optimal, lingkungan keluarga adalah sarana yang tepat sebagai sarana pengenalan (Merliana, 2010).

Keluarga adalah lingkungan dengan unit terkecil pada tatanan masyarakat sosial. Unit terkecil tersebut terdiri dari ayah, ibu dan anak. Unit ini disebut sebagai sekolah pertama bagi anak. Pada lingkungan keluarga, anak dipersiapkan untuk belajar banyak hal. Lingkungan keluarga menyiapkan anak dapat bersosialisasi dengan orang lain, sehingga pada lingkaran keluarga anak mempersiapkan diri untuk bertemu dengan dunia luar. Penanaman nilai dan sikap dilakukan oleh keluarga (Merliana, 2010).

Keluarga memiliki andil dalam membentuk nilai dan sikap anak. Tentu hal ini tak lepas dari cara orang tua mendidik anak sesuai dengan harapan norma dan nilai yang dikandung oleh masyarakat setempat. Keluarga menjadi berperan dominan dalam menstimulasi hal ini pada anak karena masa dini adalah pemebentuk dasar pertama bagi anak untuk mengembangkan seluruh potensi yang ia miliki, seperti kognitif, sosial emosional, bahasa, seni, agama dan moral, dan fisik motorik. Maria Montessori menyebut masa ini dengan masa peka anak (Ariyanti, 2016).

Masa usia dini merupakan masa penting dan krusial yang dimiliki oleh anak, karena pada masa ini anak menyerap dengan cepat apa yang dipertunjukan oleh lingkungan sekitarnya. Orang dewasa disekitar anak perlu menciptakan kondisi yang kondusif bagi tumbuh dan kembang anak yang optimal (Musi, Amal, \& Hajerah, 2015). Semua itu tak luput dari pengasuhan dari orang tua.

Mendidik anak merupakan bagian dari pola asuh. Ini merupakan faktor kunci dan pondasi bagi kehidupan anak selanjutnya. Ini tak terlepas dari cara orang tua mendidik, memelihara, mengajarkan untuk membimbing dan membentuk kepribadian dan sikap anak, menunjukkan hal baik dan benar, memberikan teladan, dan lainnya. Sehingga bisa terlatih menjadi bagian dari masyarakat yang sesuai dengan norma dan nilai budaya yang berlaku (Baiduri \& Yuniar, 2017; Landry, Smith, \& Swank, 2013; Merliana, 2010). Karena terbiasa bersosialisasi dengan lingkungan keluarga, pembiasaan dan pembudayaan di lingkungan keluarga menjadi terbawa secara tidak sadar oleh anak.

Pola asuh yang dilakukan oleh setiap keluarga berbeda satu dengan yang lain. Banyak faktor yang mempengaruhi hal tersebut, seperti budaya yang dianut oleh keluarga tersebut, faktor sosial ekonomi, pengetahuan dan pengalaman dalam merawat dan mendidik anak, pendidikan yang ditempuh sebelumnya, dan lainnya (Merliana, 2010; Santrock, 2013; Soekanto, 2002; Soetjiningsih, 2004; Sulistino, 2016; Tridhonanto, 2014; Winarti, 2019).

Pola asuh yang diterapkan oleh orang tua tidak sama dengan orang tua lainnya. Pola asuh tersebut dapat ditinjau dalam beberapa jenis. Pertama, pengasuhan otoriter, pada pola ini otoritas tertinggi berada pada orang tua, jika anak tidak menyukai yang diperintahkan orang tua, maka orang tua akan memaksakan dan harus menjalani perintah tersebut. Sehingga dalam pola pengasuhan otoriter, anak merasa terkekang, kurangnya kebebasan. Kedua, pengasuhan demokratis, pola ini terlihat adanya kehangatan dan musyawarah antara orang tua dan anak, sehingga dalam pola pengasuhan demokratis anak lebih bersahabat, mampu diajak kerjasama, dan hal-hal positif lainnya dari pola pengasuhan demokratis. Ketiga, pengasuhan permisif, pola pengasuhan ini memberikan kebebasan kepada anak tanpa adanya dampingan dan kontrol yang wajar dari orang tua. Pola pengasuhan permisif, orang tua tidak menerapkan aturan yang tegas dan konsisten, sehingga anak merasa leluasa melakukan sesuka hatinya (Baumrind, 1966; Baumrind, 1971; Kholifah, 2018; Susanto, 2011).

Variasi budaya perlu ditinjau untuk melihat sisi pengasuhan yang diberikan oleh orang tua dalam perbedaan budaya, perbedaan ini tentunya dipengaruhi oleh persepsi sosial disekitar anak dan tindakan yang ingin dicapai untuk anak dalam memegang nilai dan norma (Februhartanty.,dkk 2007). Landasan teori yang penulis cantumkan adalah pola pengasuhan yang diterapkan oleh orang tua dalam mendidik anak sesuai dengan budaya yang dianut dalam aspek kepribadian yang dimiliki oleh anak. Hal ini penulis lakukan guna mempersempit ruang kajian yang disajikan. Penulis ingin meninjau cara pengasuhan orang tua dari berbagai suku di Indonesia. 


\section{METODE PENELITIAN}

Jenis penelitian yang dilakukan menggunakan desain penelitian kajian literatur, yang digunakan untuk lebih mengerti dan memiliki pandangan mengenai suatu kajian (Borg \& Gall, 1983), sehingga penulis mengumpulkan bahan kajian yang diperlukan, menggarisbawahi hal yang penting, dan melakukan pengolahan kembali penelitian (Zed, 2003 dalam Maulana, Kurniati, \& Yulindrasari, 2020).

Dalam melakukan kajian literatur ada empat langkah yang harus diperhatikan. Pertama, karena penelitian studi pustaka adalah penelitian melalui kajian-kajian penelitian sebelumnya, sehingga penulis tidak turun ke lapangan, atau pun penelitian yang peneliti lakukan bukan berupa numerik. Kedua, karena penulis tidak langsung turun ke lapangan dan hanya menggunakan referensi yang sudah tersedia, sehingga penelitian ini bersifat "siap pakai". Ketiga, daftar pustaka bukan primary sources, sehingga dominan menggunakan secondary sources. Keempat, kondisi bahan referensi tidak dibatasi oleh ruang dan waktu (Zed dalam Maulana, Kurniati, \& Yulindrasari, 2020).

Peneliti melakukan penelaahan dan pengeksplorasian melalui buku, jurnal, dan berbagai dokumen yang relevan baik secara online maupun offline sehingga dapat menunjang penelitian ini.

Hasil akhir dari penelitian ini berupa gagasan mengenai perbedaan pola asuh yang diterapkan oleh orang tua ditinjau dari suku yang diikuti, sehingga memberikan gambaran bahwa setiap suku ada pola asuh dominan yang diaplikasikan oleh orang tua untuk anaknya tak terlepas dari pengaruh suku dan budayanya.

\section{HASIL DAN PEMBAHASAN}

Salah satu yang memengaruhi pola pengasuhan adalah suku dan budaya yang dianut oleh keluarga. Pengembangan nilai kebudayaan kepada anak paling efektif dikembangkan pada pola asuh yang diterapkan (Riany, Meredith, \& Cuskelly, 2016). Ini disebabkan karena intensifnya interaksi yang dilakukan oleh orang tua kepada anak dan terjadinya hubungan timbal balik, membuat anak memahami lebih cepat budaya yang ada pada keluarganya sendiri, karena pola asuh merupakan kegiatan yang sangat kompleks pada kehidupan anak (Baumrind, 1978; Luther, 2007).

Beraneka ragam suku di Indonesia, seperti Minangkabau, Batak, Bugis, Jawa, Dayak, Sunda, Sasak dan lainnya memiliki tatanan aturan dan nilai tersendiri. Sehingga faktor suku di Indonesia merupakan faktor potensial untuk ditelusuri (Situngkir, 2008), karena keanekaragaman yang dimiliki oleh bangsa merupakan kekuatan tersendiri yang patut dibanggakan.

Suku di Indonesia, tak terlepas dari stereotip yang melekat padanya. Seperti, suku Minang di stereotipkan dengan sering belajar ke surau dan suka berdagang, suku Jawa di stereotipkan orang yang rajin dan gigih, suku Batak di stereotipkan sebagai orang yang tegas, lugas dan keras (Kato, 2005; Sanguni, 2014).

Pola pengasuhan orang tua sangat mempengaruhi dalam mendidik anak (Laundry, Smith \& Swank, 2013), dan pola pengasuhan yang diberikan juga dipengaruhi oleh faktor suku dan budaya (Merliana, 2010; Santrock, 2013; Soekanto, 2002;
Soetjiningsih, 2004; Sulistino, 2016; Tridhonanto, 2014; Winarti, 2019). Chen, Fu, dan Yiu (2019) mengungkapkan bahwa budaya, norma, nilai yang ada pada masyarakat menentukan praktek dan pola pengasuhan yang diberikan. Pengasuhan dan budaya tak bisa dipisahkan, sebab budaya adalah sesuatu hal yang membuat mereka menjadi manusia yang bernilai dan mereka percaya dengan budaya yang mereka dapatkan, sehingga dia dapat beradaptasi di masyarakat. Pola pengasuhan didapatkan dari pengalaman sebelumnya, sehingga mereka menurunkan pola asuh yang telah ia dapatkan sebelumnya (Chen, Fu, \& Yiu, 2019; Khodijah, 2018). Beberapa hasil temuan melalui penelusuran referensi dan analisis, serta pembahasan hasil dari penelitian kajian literatur.

Pola Asuh ditinjau dari berbagai Suku

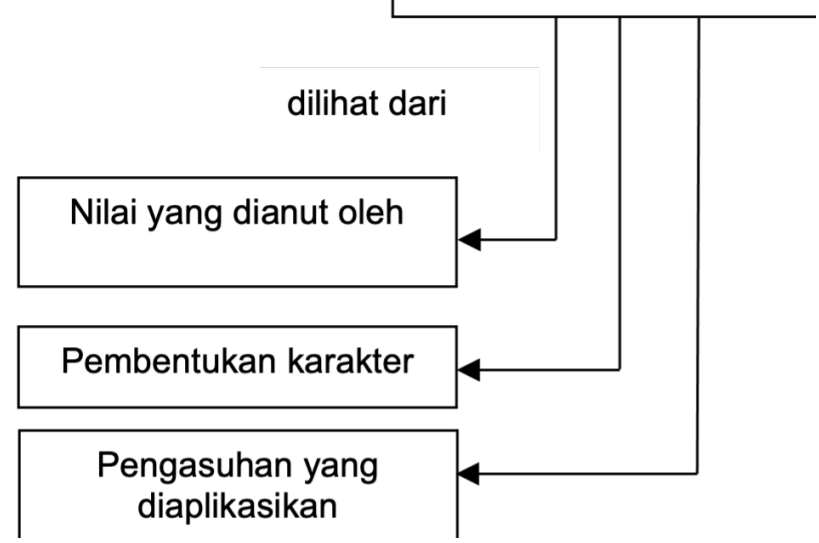

Gambar 1. Tinjauan yang dianalisis dari penelitian 


\section{Pola Asuh Orang Tua pada Suku Minangkabau}

Suku Minangkabau mendiami daerah Sumatera Barat. Dalam tradisinya, suku Minangkabau dikenal dengan suko marantau (suka bermigrasi) untuk mencari kehidupan dan kesempatan hidup yang lebih baik. Merantau merupakan cara ideal dalam mencapai kesuksesan dan kematang bagi laki-laki Minangkabau (Trisa, Suprijono, \& Jacky, 2018). Suku Minangkabau juga dikenal sebagai suku terbesar yang menganut garis keturunan ibu, yang disebut juga dengan matrilineal (Sukamto \& Suci, 2018). Sistem kekerabatan matrilineal di Minangkabau, rumah gadang diisi oleh keluarga besar, bukan hanya terdiri dari ayah, ibu, dan anak, tetapi semua garis satu keturunan dari garis matrilineal (Koentjoroningrat, 1993; Mulia, 2016). Suku Minangkabau juga dikenal kental dalam budaya dan norma keislamannya (Chandra, 2004). Falsafah yang dianut suku Minangkabau adalah adat basandi syarak, syarak basandi kitabullah, artinya adat bersendi oleh agama, agama bersendi oleh Al-Qur'an.

Dari sejumlah kajian pustaka yang ditelusuri, dalam pengasuhan, baik mengasuh anak laki-laki ataupun perempuan, tidak ada perbedaan yang kentara (Rahayu \& Amanah, 2016), dalam arti pengasuhan tidak dibedakan dalam gender. Semua diberikan sama rata. Lebih lanjut, Rahayu dan Amanah (2016) memaparkan orang tua dengan suku Minang hanya membedakan pakaian dan mainan anak lakilaki dan perempuan. Namun dalam beberapa literatur menyebutkan bahwa anak perempuan di Minangkabau sangat diperhatikan sekali. Anak perempuan di Minangkabau diatur dari bagaimana ia berjalan, duduk, berpakaian, bergaul, berdiri, diam, berkomunikasi, melihat, bekerja, bertanya, dan berperilaku (Astuti, 2016; Iskandar, Mardianto \& Putra, 2014).

Orang tua di suku Minang dalam memberikan pengawasan tergantung pada usia anak (Rahayu \& Amanah, 2016). Maksudnya adalah orang tua memberikan tanggung jawab kepada anak yang dirasa sudah mampu melakukannya sehingga hanya diawasi. Berbeda dengan usia anak yang masih kecil, orang tua suku Minang akan memberikan perhatian dan pengawasan yang penuh.

Minangkabau menganut sistem kekerabatan matrilineal, pada sistem kekerabatan ini anak mengikuti garis keturunan ibu. Pada suku Minangkabau, pengasuhan dibantu oleh seluruh elemen keluarga ibu. Jadi, pengasuhan tidak hanya tugas orang tua (ibu dan ayah), tetapi dibantu oleh keluarga dari ibu, seperti mamak (saudara laki-laki ibu) bertanggung jawab dalam pengasuhan kamanakan (keponakan). Mamak adalah sebutan untuk saudara laki-laki kandung ibu, baik kakak atau adik dari ibu (Nafkhatul, 2017). Seperti ungkapan Minangkabau, "anak dipangku, kamanakan dibimbiang" (Sjarifoedin, 2014; Trisa, Suprijono, \& Jacky, 2018), maksudnya adalah selain memperhatikan dan mempedulikan anak sendiri, mamak juga membimbing anak dari saudara-saudara perempuannya. Pola pengasuhan di Minangkabau, peran ayah dapat digantikan oleh mamak. Namun, bukan berarti peran ayah tidak penting dalam pengasuhan, tetapi ayah memiliki tugas utama, yakni: mencari nafkah dan mengolah tanah pustaka istrinya (Natin, 2008). Sebagaimana ungkapan Minang mengatakan bahwa, "Mamak karena adat, bapak karena darah." Jadi, unsur pertama dan penting adalah ayah, kedua mamak.

Dalam pembentukan karakter anak, temuan Eliza (2017) menunjukkan bahwa keluarga Minangkabau mendidik melalui dongeng-dongeng tradisional, cerita legenda yang mengandung nilai dan kearifan lokal Minangkabau. Membentuk karakter melalui cerita legenda atau mitos merupakan salah satu bentuk pendidikan, dan hal itu merupakan fungsi pedagogi. Cerita dan nilai yang terdapat dalam cerita tersebut merupakan cara mendidik anak (Campbell, Cousineau, \& Brown, 1990), misalnya dalam kisah Malin Kundang, nilai dan cerita tersebut terefleksikan dalam sistem pengasuhan. Cerita mitos dan legenda adalah klasik pada setiap budaya, karena mitos adalah salah satu kebutuhan pada masyarakat dalam menjawab persoalan yang belum mereka ketahui jawabannya (Yunarti \& Rahmadani, 2017). Selain itu, orang tua di Minangkabau sering memberikan pembelajaran kepada anaknya secara lisan, baik secara menasehati ataupun menunjukkan dengan perilaku dan tindakan (Trisa, Suprijono, \& Jacky, 2018).

Orang tua Minangkabau juga memberikan pendidikan agama kepada anaknya untuk membentuk budi dan tata krama yang baik. Selain sekolah formal, orang tua juga mengarahkan anaknya ka surau (ke mesjid). Surau selain menjadi tempat untuk belajar agama, fungsi lain surau bisa untuk tempat latihan silek (silat), menjadi pusat budaya, pelengkap dari rumah gadang, tradisional institusi yang memiliki peran dan fungsi agama dan budaya sosial dalam kehidupan Minangkabau dan pusat informasi (Haviz, 2017, Mawangir, 2016).

Dalam berbahasa, baik yang mendiami daerah Sumatera Barat maupun diluar Sumatera Barat, keluarga Minangkabau tetap menjunjung tinggi dan melestarikan bahasa ibu (Trisa, Suprijono, \& Jacky, 2018). Walau keluarga Minangkabau yang tinggal diluar Sumatera Barat, tetap fasih berbahasa 
Minangkabau. Komunikasi yang digunakan anak diatur dalam budaya, pertama kato mandaki, digunakan berbahasa dengan orang yang lebih dewasa dari anak. Kedua, kato manurun, digunakan kepada orang yang lebih kecil dari anak. Ketiga, kato malereang, digunakan pada lawan bicara yang sangat disegani. Keempat, kato mandata, ini digunakan pada lawan bicara yang sama besar (Nauri, dkk., 2018).

Pola pengasuhan yang diaplikasikan oleh orang tua suku Minang ialah mengkolaborasikan dan menyeimbangkan antara adat dan agama. Ketek taraja - raja, gadang tabao - bao, sampai gaek barubah tido (kecil terbiasa, besar terbawa - bawa, hingga tua tidak berubah) (Kosim, Samad, \& Nasution, 2018).

\section{Pola Asuh Orang Tua pada Suku Jawa}

Suku Jawa dikenal sebagai suku yang menganut bilateral, dalam artian dapat mengikut bapak dan ibu. Jika anak terlahir pada suku Jawa dengan status sosial ekonomi bergolongan rendah, maka anak dianggap sebagai aset yang dapat memberikan kebermanfaatan nantinya untuk membantu orang tua dan keluarga di masa yang akan datang, sedangkan anak yang lahir pada keluarga status sosial ekonomi bergolong tinggi, anak dianggap sebagai prestasi yang dimiliki (Kuntoro, Peterson, \& Slaughter, 2017; Zeitlin, Megawangi, Kramer, Colleta, Babatunde \& Garman, 1995).

Suku Jawa dalam menerapkan pola asuh memiliki istilah dan prinsip tertentu. Dalam membentuk anak menjadi Jawa ideal, biasanya dilakukan dalam proses interaksi anak dan orang tua sehingga dapat membentuk anak lebih baik atau istilah Jawa dikenal adalah dadi wong (Geertz, 1983). Geertz (1983) menambahkan bahwa pola asuh suku Jawa memegang teguh dua prinsip, ini disebut dengan nilai Kejawen, nilai tersebut berisi tata krama atau hormat dan kerukunan. Isin, wedi, dan sungkan (malu, takut dan sungkan) adalah bagian dari tata krama atau hormat. Nilai kerukunan, tenggang rasa, menjauhi konflik merupakan nilai yang dipegang oleh suku Jawa (Chandra, 2004).

Pengasuhan yang diterapkan oleh suku Jawa yang dipaparkan oleh Baiduri \& Yuniar (2017) mengungkapkan bahwa ada tiga model pengasuhan yang diterapkan. Pertama, pola pengasuhan permisif, dengan membiarkan atau mengabaikan. Kedua, memberikan perintah secara detail, tidak emosional dan tidak ada ancaman ataupun hukuman. Ketiga, model pengasuhan dengan menakut-nakuti, dalam bahasa Jawa disebut dengan ngeden - ngedeni, maksudnya adalah orang tua memberikan hal-hal diluar nalar untuk menakut-nakuti anak agar anak menurut.

Dalam pola komunikasi, pengasuhan yang terlihat pada nilai budaya Jawa adalah menggunakan bahasa kromo. Hal tersebut ditujukan pada orang yang lebih dewasa dari anak. Hasil penelitian mengenai orang tua bersuku Jawa memaparkan bahwa orang tua di suku Jawa menekankan kepada anaknya untuk bersikap sopan, berbahasa halus, dan penuh penghargaan kepada yang lebih tua (Kuntoro, Peterson, \& Slaughter, 2017). Penelitian baru - baru ini yang dilakukan oleh Smith - Hefner dalam Winarti (2018), ditemukan bahwa dari 206 siswa, hanya 11 persen yang menggunakan bahasa krama kepada orang yang lebih dewasa, selebihnya menggunakan bahasa Indonesia.

Koentjaraningrat mengungkapkan bahwa keluarga suku Jawa lekat dengan keagamaan dalam arti religius (Zeitlin, Megawangi, Kramer, Colleta, Babatunde \& Garman, 1995). Ini ditunjukan dalam penelitian Rahayu dan Amanah (2016) yang memaparkan bahwa orang tua suku Jawa sangat memperhatikan pendidikan agama anak-anaknya dengan mengikuti pembelajaran di musholla atau mesjid. Karena, orang tua ingin membentuk karakter yang lebih baik untuk anak-anaknya.

\section{Pola Asuh Orang Tua pada Suku Batak}

Masyarakat yang paling banyak menganut suku Batak terdapat di Sumatera Utara. Sistem kekerabatan yang dianut pada suku ini adalah patrilineal, artinya suku Batak menganut garis keturunan ayah. Dalam sistem ini anak laki - laki dan perempuan menyandang hak dan kewajiban yang berbeda terhadap marga mereka (Firmando, 2020; Rahayu \& Amanah, 2016). Penemuan lebih lanjut menjelaskan lebih lanjut bahwa anak laki - laki Batak, sepanjang hidupnya hanya mengenal marga ayahnya, sedangkan anak perempuan nantinya akan mengenal dua marga. Pertama, marga ayahnya; dan kedua, marga suaminya. Posisi perempuan Batak dalam posisi ambigu, walaupun berhubungan dengan marga tersebut, namun tidak pernah menjadi anggota yang utuh. (Firmando, 2020; Siregar, 2013).

Falsafah yang dijunjung tinggi oleh suku Batak ialah hagabeon (diberkati atas keturunan), hamoraon (kekayaan), dan hasangapan (kehormatan) (Harahap \& Siahaan, 1987). Suku Batak lebih suka untuk berkelompok dan bersama-sama, baik dalam satu marga atau berhubungan darah ataupun satu relasi kerabat hubungan pernikahan (Chandra, 2004).

Karena suku Batak suka berkelompok dalam keluarga besar, hal itu dapat memberikan dukungan 
emosional, dukungan dalam bentuk asisten atau bergantian dalam mendidik anak, dukungan dalam memberikan nasihat, saran untuk lebih baik, dan memberikan rasa kasih sayang, karena menghabiskan waktu bersama - sama (Fauzia, Nauly, \& Purba, 2016)

Dalam suku Batak, laki - laki adalah penting, karena selain penerus marga atau nama keluarga, laki - laki di suku Batak juga memiliki tanggung jawab untuk meneruskan keturunan, bertanggung jawab dan hidup mandiri (Rahayu \& Amanah, 2016). Tapi tidak membuat peranan anak perempuan menjadi hilang pada suku Batak. Suku Batak juga menjunjung dan mengangkat anak perempuan. Anak perempuan juga sangat penting peranannya di suku Batak, yakni sebagai pengurus dan pemerhati orang tua yang telah lanjut usia (Firmando, 2020).

Orang tua suku Batak sangat memperhatikan pendidikan putra - putrinya. Mereka selalu menekankan pendidikan yang baik untuk keturunannya. Sehingga orang tua suku Batak, dalam kegiatan bekerja bukan hanya untuk mempertahankan hidup, juga untuk memperoleh kehidupan yang lebih baik bagi dirinya dan keturunannya, sehingga mereka rela untuk menyimpan pundi-pundi rupiah untuk pendidikan yang mapan bagi anak - anaknya (Chandra, 2004). Sehingga budaya pergi ke daerah orang, memang menjadi tradisi bagi suku Batak, ia menginginkan agar anak-anaknya memiliki kehidupan yang lebih baik dibanding dirinya. Dengan hal tersebut, dapat membuat keluarga Batak dihormati (Sutantoputri, Murniati, \& Purwanti, 2015).

Dalam pembentukan watak anak, suku Batak harus tegar dan kuat, mereka tidak boleh menunjukkan kelemahan ataupun afektif mereka. Ini di kenal dengan creedo atau menangis di dalam hati). Jika anak suku Batak menunjukkan kelemahannya ataupun gagal di salah satu aspek kehidupan, itu dapat dicemoohkan oleh masyarakat dan bahkan keluarga sendiri. Sehingga suku Batak memiliki internalisasi dalam dirinya adalah menjadi "nomor satu". Suku Batak memiliki jiwa kompetitif yang kuat, sehingga memiliki keinginan menjadi yang pertama pada semua aspek. Jika gagal, mereka akan berusaha lebih keras lagi, dan tidak menunjukkan kegagalan mereka, karena menjadi lemah dan menangis itu bukan suatu jiwa dari suku Batak (Fauzia, Nauly, \& Purba, 2016).

Orang tua suku Batak juga melakukan pemberian cerita, dongeng dan mitos kepada anak - anaknya, seperti cerita Si Beru Rengga Kuning, di dalam cerita ini nilai moral yang terkandung dan dapat membentuk sikap dan moral anak (Karo, 2018). Walaupun kejadiannya tidak sebenar - benarnya, namun mitos tersebut dapat diandalkan dalam masyarakat (Karo, 2018).
Dari analisis pola pengasuhan ditinjau dari beberapa suku di Indonesia, peneliti merangkumnya seperti pada tabel 1-3 berikut ini

Tabel 1.

Pola Pengasuhan ditinjau dari Suku Minangkabau

Pola Pengasuhan ditinjau dari Suku Minangkabau

Nilai yang dianut Suku Minang berpegang teguh dengan falsafah yang diikuti, yakni adat basandi syarak, syarak basandi kitabullah.

\begin{tabular}{ll}
\hline $\begin{array}{l}\text { Pembentukan } \\
\text { karakter }\end{array}$ & $\begin{array}{l}\text { Orang tua suku Minang suka } \\
\text { memberikan cerita berupa legenda, } \\
\text { dongeng, mitos, lainnya. Selain itu, } \\
\text { ketauladanan dan tindakan dari } \\
\text { orang tua itu sendiri juga diperlukan. }\end{array}$ \\
\hline $\begin{array}{l}\text { Pengasuhan } \\
\text { yang }\end{array}$ & $\begin{array}{l}\text { Orang tua suku Minang } \\
\text { diaplikasikan }\end{array}$ \\
$\begin{array}{l}\text { menyeimbangkan antara } \\
\text { anak di suku Minang tidak hanya } \\
\text { diasuh oleh keluarga inti, namun ada } \\
\text { peran mamak dalam mengayomi } \\
\text { anak. }\end{array}$ \\
\hline
\end{tabular}

Tabel 2.

Pola Pengasuhan ditinjau dari Suku Jawa

\begin{tabular}{|c|c|}
\hline \multicolumn{2}{|c|}{ Pola Pengasuhan ditinjau dari Suku Jawa } \\
\hline Nilai yang dianut & $\begin{array}{l}\text { Suku Jawa berpegang pada prinsip } \\
\text { kerukunan. Nilai kejawen terdiri dari } \\
\text { isin, wedi, sungkan. }\end{array}$ \\
\hline $\begin{array}{l}\text { Pembentukan } \\
\text { karakter }\end{array}$ & $\begin{array}{l}\text { Orang tua suku Jawa mengajarkan } \\
\text { sedari dini tata krama kepada } \\
\text { anaknya. Gaya bicara kepada orang } \\
\text { yang lebih besar berbeda dengan } \\
\text { gaya bicara dengan teman sesama. } \\
\text { Selain itu, orang tua pada suku Jawa } \\
\text { juga memperhatikan pendidikan } \\
\text { agama pada anaknya. }\end{array}$ \\
\hline $\begin{array}{l}\text { Pengasuhan } \\
\text { yang } \\
\text { diaplikasikan }\end{array}$ & $\begin{array}{l}\text { Dalam pengasuhan, orang tua } \\
\text { tidak terlalu emosional, dan tidak } \\
\text { ada hukuman yang terlalu berat } \\
\text { untuk anaknya. Orang tua di suku } \\
\text { Jawa, dalam mengasuh anak suka } \\
\text { ngeden-ngedeni atau menakut- } \\
\text { nakuti. }\end{array}$ \\
\hline
\end{tabular}

Tabel 3.

Pola Pengasuhan ditinjau dari Suku Batak

\begin{tabular}{ll}
\hline \multicolumn{2}{c}{ Pola Pengasuhan ditinjau dari Suku Batak } \\
\hline Nilai yang dianut & $\begin{array}{l}\text { Suku Batak dalam falsafah } \\
\text { hidupnya memiliki tujuan hagabeon, } \\
\text { hamoraon, dan hasangapan. }\end{array}$ \\
\hline $\begin{array}{ll}\text { Pembentukan } \\
\text { karakter }\end{array}$ & $\begin{array}{l}\text { Suku Batak memiliki jiwa } \\
\text { kompetetitif, sehingga mengasah } \\
\text { jiwa tegar sedari dini pada anaknya. } \\
\text { Selain itu, orang tua suku Batak } \\
\text { juga memberikan cerita-cerita } \\
\text { mitos, legenda dan dongeng dalam } \\
\text { membentuk kepribadian anak. }\end{array}$ \\
\hline $\begin{array}{l}\text { Pengasuhan } \\
\text { yang } \\
\text { diaplikasikan }\end{array}$ & $\begin{array}{l}\text { Orang tua suku Batak, selain } \\
\text { mengikuti adat yang kental, mereka } \\
\text { juga mensinergikan dengan agama } \\
\text { yang dianut. }\end{array}$ \\
\hline
\end{tabular}




\section{PENUTUP}

Dari berbagai tinjauan referensi dan hasil penelitian, ditemukan berbagai hal yang membedakan pola pengasuhan suku satu dengan yang lainnya. Perbedaan tersebut mencakup dari nilai dan budaya yang dianut, pembentukan karakter anak, dan pola pengasuhan yang dilakukan terhadap anak ini ditinjau dari aturan dan nilai budaya setempat, pola komunikasi yang digunakan oleh orang tua, serta tujuan, visi, dan misi dari budaya yang mempengaruhi cara orang tua mendidik anak. Walaupun demikian, hal tersebut memberikan variasi dalam pola pengasuhan yang dilakukan oleh orang tua di Indonesia. Hal ini memungkinkan untuk orang tua merefleksikan kembali dan mengambil hal- hal positif dalam pengasuhan yang diterapkan pada anak dalam perspektif suku dan budaya.

Dalam keanekaragaman suku dan budaya, sepatutnya wajib kita lestarikan. Namun, jika ada hal yang melenceng dari prinsip ideal, sebaiknya dijadikan evaluasi kedepan dan mengambil sisi positif. Artikel ini dapat menambah wawasan mengenai pola pengasuhan untuk anak usia dini.

\section{DAFTAR PUSTAKA}

Ariyanti, T. (2016). Pentingnya pendidikan anak usia dini bagi tumbuh kembang anak. Dinamika: Jurnal Ilmiah Pendidikan Dasar, 8 (1), 50-58. DOI: 10.30595/dinamika.v8i1.943

Astuti, F. (2016). Esensi nilai-nilai sumbang duo baleh dalam tari perempuan Minangkabau. Garak jo Garik: Jurnal Pengkajian dan Penciptaan Seni, 12 (2), 82-102. Retrieved from https://journal. isi-padangpanjang.ac.id/index.php/Garak/ article/view/292/252

Baiduri, R. \& Yuniar, A. (2017). Pola pengasuhan keluarga etnis Jawa hasil pernikahan dini di Deli Serdang. Jurnal Antropologi Sumatera, 15 (1), 252-258. Retrieved from https://jurnal. unimed.ac.id/2012/index.php/jas/article/ view/8624/7172

Baumrind, D. (1966). Effect of authoritative parental controlon child behavior. Child Development, 37 (4), 887-907. DOI: 10.2307/1126611.

Baumrind, D. (1971). Current pattern of parental authority. Developmental Psychology Monograph, 4 (1), 1-103. DOI: 10.1037/ h0030372.

Baumrind, D. (1978). Parental diciplinary patterns and social competence in children. Youth and Society Journal, 9, 239-267. DOI:10.1177/0044118X7800900302

Borg, W. R., \& Gall, M. D. (1983). Educational Research: An Introduction. Broadway, NY: Longman Inc.

Badan Pusat Statistik. (2020). Proyeksi Penduduk Indonesia 2015-2045 Hasil SUPAS 2015. Retrieved from https://www.bps.go.id .

Campbell, J., Cousineau, P., \& Brown, S. L. (1990). The Hero's Journey: Joseph Campbell on His Life and Work. San Francisco: Harper \& Row.
Chandra, J. S. (2004). Notions of critical thinking in Javanese, Batak Toba, Minangkabau culture. In B. N. Setiadi, A, Supratinya, W. J. Lonner, \& Y. H. Poortinga (Eds), Ongoing themes in psychology and culture: Proceedings from the 16th International Congress of the International Assosiation for Cross Cultural Psychology. https://scholarworks.gvsu.edu/ iaccp_papers/258

Chen, X., Fu, R. \& Yiu, W. Y. V. (2019). Culture and Parenting. Los Angeles: Routledge.

Eliza, D. (2017). Pengembangan model pembelajaran karakter berbasis cerita tradisional Minangkabau untuk anak usia dini. Jurnal Pedagogi, 3 (3), 153-163. DOI: http:10.30651/pedagogi.v3i3b.

Fauzia, R., Nauly, M., \& Purba, R. M. (2016). Social support of Toba Bataknese mother in children's education. Advances in Social Science, Education and Humanities Research (ASSEHR), 81, 509-512. DOI: 10.2991/ icosop-16.2017.32

Februhartanty, J., Usfar, A. A., Dianawati, E., Fransisca, D. O., Roshita, A., \& Fahmida, U. (2007). Psychosocial care and nutritional status of children aged 6-36 months among patrilineal (Karo) and matrilineal (Minangkabau) household in Jakarta. Asia Pacific Journal Clinical Nutrition, 16 (2), 293 - 300. DOI: 10.1163/22134379-90003484 .

Firmando, H. B. (2020). Potret pengarusutamaan gender dalam kehidupan keluarga Batak Toba di Tapanuli Utara. Jurnal IImiah Sosiologi Agama, 3 (1), 47 - 62. DOI: 10.30829/jisa. v3i1.7394

Geertz, H. (1983). Keluarga Jawa. Jakarta: PT Raja Grafindo Persada. 
Harahap, B. H., \& Siahaan, H. M. (1987). Orientasi Nilai - nilai Budaya Batak Suatu Pendekatan terhadap Perilaku Batak Toba Angkola Mandailing. Jakarta: Sanggar Willem Iskandar.

Haviz, M. (2017). Designing and developing a new model of education surau and madrasah Minangkabau Indonesia. Jurnal Pendidikan Islam, 6 (1), 79 - 100. DOI: 10.14421/ jpi.2017.61.79-100.

Iskandar, S. P., Mardianto., \& Putra, Y. Y. (2014). Konsep sumbang duo baleh dalam tinjauan psikologi. Jurnal RAP UNP, 5 (2), 180-191. DOI: 10.24036/rapun.v5i2.6632

Karo, K. B. (2018). Moral value assessment and character education in folklore in Karo district. Jurnal Metholanguage Universitas Methodist Indonesia, 3 (2), 28 - 33.

Kato, T. (2005). Adat Minangkabau dan Merantau dalam Perspektif Sejarah. Jakarta: PT. Penerbitan Balai Pustaka.

Khodijah, N. (2018). Pendidikan karakter dalam kultur Islam Melayu (Studi terhadap pola asuh orang tua, faktor-faktor yang mempengaruhinya, dan pengaruhnya terhadap religiusitas remaja pada suku Melayu Palembang). Tadrib, 4(1), 21-39. DOI: 10.19109/Tadrib.v4i1.1949

Kholifah. (2018). Pengaruh pola asuh orang tua terhadap kecerdasan emosional AUD di TK Muslimat NU 1 Tuban. Jurnal Pendidikan Anak, 7(1), 61-75. DOI: 10.21831/jpa.v7i1.24446

Koentjoroningrat. (1993). Manusia dan Kebudayaan di Indonesia. Jakarta: Djambatan.

Kosim, M., Samad, D., \& Nasution, I. (2018). Melahirkan generasi shaleh dan berbudaya. Padang: Imam Bonjol Padang.

Kuntoro, I. A., Peterson, C. C., \& Slaughter, V. (2017). Culture, parenting, and children's theory of mind development in Indonesia. Journal of Cross Cultural Psychology, 48 (9), 1389-1409. DOI: $10.1177 / 0022022117725404$

Landry, S. H., Smith, K. E., \& Swank, P. R. (2013). The importance of parenting during early childhood for school age developmet. Journal of Developmental Neuropsychology, 24 (2-3), 559591. DOI: 10.1080/87565641.2003.9651911

Maulana, R. E., Kurniati, E., \& Yulindrasari, H. (2020). Apa yang menyebabkan rendahnya keberadaan guru laki-laki di PAUD. Visi: Jurnal IImiah PTK PNF, 15 (1), 23-32. DOI: 10.21009/ JIV.1501.3.

Mawangir, M. (2016, July). The surau: traditional education in Minangkabau. PROCEEDINGS:
The 9th International Congress of the Asian Philosophical Association (ICAPA), 313-327.

Merliana, N. (2010). Pola pengasuhan pada komunitas adat Giri Jaya. Jurnal Patanjala, 2 (2), 241-257.

Mulia, P. I. (2016). Pola komunikasi keluarga etnis Minangkabau perantau terhadap anak lakilaki dan anak perempuan dalam sistem kekerabatan matrilineal (studi pada etnik Minangkabau di Kelurahan Tanjung Aman Kecamatan Kotabumi Selatan Kabupaten Lampung Utara). Skripsi tidak diterbitkan. Lampung: Fakultas IImu Sosial dan Politik Universitas Lampung.

Musi, M. A., Amal, A., Hajerah. (2015). Pengasuhan anak usia dini perspektif nilai budaya pada keluarga Bajo di Kabupaten Bone. Jurnal Penelitian Pendidikan Insani, 18 (1), 39-49. DOI: $10.26858 /$ ijes.v18i1.3601

Nafkhatul, W. (2017). Persepsi kemenakan terhadap pengasuhan mamak dalam etnis Minangkabau. Skripsi tidak diterbitkan. Padang: Universitas Andalas.

Natin, S. (2008). Perubahan sosial kedudukan dan peran mamak terhadap anak dan kemenakan di ranah Minang. Mimbar Hukum, 20 (2), 1-17. DOI: 10.22146/jmh.16306.

Nauri, S. W., Agustina., \& Juita, N. (2018). Pronomina dalam langgam kato nan ampek dalam kaba klasik Minangkabau. Jurnal Bahasa dan Sastra, 5 (2), 1-12. DOI: 10.24036/895830

Riany, Y. E., Meredith, P., \& Cuskelly, M. (2016). Understanding the influence of traditional cultural values on Indonesian parenting. Journal of Marriage \& Family Review, 53 (3), 1-29. DOI: 10.1080/01494929.2016.1157561

Rahayu, M. D., \& Amanah, S. (2016). Faktor - faktor yang berhubungan dengan pola asuh anak pada etnis Minang, Jawa, dan Batak. Jurnal Penyuluhan, 6 (2). DOI: 10.25015/penyuluhan. v6i2.11449

Santrock, J. W. (2013). Life-span development fourteenth. McGraw-Hill. New York, USA: Companies Edition Americas.

Sanguni, F. (2014). Pemberian strereotip gender. Musawa: Journal for Gender Studies, 6 (2), 195-224. Retrieved from https://jurnal.iainpalu. ac.id/index.php/msw/issue/archive

Siregar, M. H. (2013, Oktober). Quasy equality in Angkola Bataknese community: challenging the patriarchal domination. SEMINAR: Legal Aspect of Islam in Indonesia. 
Situngkir, H. (2008). Constructing the phylomemetic tree, case of study: Indonesian traditioninspired building. SSRN Electronic Journal, 1 - 9. DOI: 10.2139/ssrn.1104060 .

Sjarifoedin, A. (2014). Minangkabau. Jakarta: PT. Gria Media Prima.

Soekanto, S. (2002). Sosiologi suatu pengantar. Jakarta: Yayasan Penerbit Universitas Indonesia.

Soetjiningsih. (2004). Tumbuh kembang anak. Jakarta: EGC.

Sukamto, K. E., Suci, E. S. T., \& Sri, E. (2018). Minangkabau women in Jakarta: their perceptions of Minang language, Indonesia language, and Minang culture. Jurnal Kata: Penelitian tentang IImu Bahasa dan Sastra, 2 (2), 219-227. DOI: 10.22216/jk.v2i2.3221

Sulistino, E. (2016). Pengasuhan anak pada single parent. Disertasi Tidak Diterbitkan. Bandung: Universitas Pendidikan Indonesia

Sung, H. Y. (2010). The influence of culture on parenting practices of East Asian families and emotional intelligences of older adolescents. Journal of School Psychology International, 31 (2), 199-214. DOI: 10.1177/0143034309352268

Susanto, A. (2011). Perkembangan Anak Usia Dini. Jakarta: Prenada Media Group.

Sutantoputri, N. W., Murniati, J., \& Purwanti, M. (2015). Educational aspiration, attributions, and motivational goals: a comparative study of 5 sub - ethnicities in Indonesia. Asian Journal of Educational Research, 3 (2), 76 -85.
Tridhonanto, A. (2014). Mengembangkan pola asuh demokratis. Jakarta: Gramedia.

Trisa, Y., Suprijono, A., \& Jacky, M. (2018). Kearifan lokal budaya Minang "dima bumi di pijak, disitu langik di junjuang” dalam kasus etnopedagogi kasus perantau Minang di Surabaya. Journal of Education Technology and Innovation, 1 (2), 62 - 85. DOI: 10.31537/jeti.vli2

Winarti, O. (2018). Language shift of krama to Bahasa Indonesia among Javanese youths and it's relation to parents' social class. Jurnal Studi Komunikasi, 2 (3), 290-300. DOI: 10.25139/ jsk.v2i3.186

Winarti, W. (2019). Hubungan antara tingkat pendidikan orang tua dengan orientasi pola asuh anak usia dini (Studi di RA Al Karimy Kec. Kutorejo Kab. Mojokerto). The Annual International Conference on Islamic Education, Proceeding 4 (1), 261-270. Retrieved from http://jurnal.stitnualhikmah.ac.id/index.php/ proceedings/article/view/393

Yunarti \& Rahmadani, W. (2017). Nilai edukasi mitos dan relevansinya dengan penanaman nilai pada keluarga Minangkabau kontemporer. Jurnal Antropologi: Isu - isu Sosial Budaya, 19 (1), 55 - 56. DOI: 10.25077/jantro.v19. n1.p55-65.2017.

Zeitlin, M. F., Megawangi, R., Kramer, E. F., Colleta, N. D., Babatunde, E. D., \& Garman, D. (1995). Strengthening the Family: Introduction for International Development. New York: United Nations Universiy Press 
34 VISI : Jurnal IImiah PTK PNF - Vol. 16 No. 1, Juni 2021 